I vote NOTA: Ideological Expanses of Partisanship in India

\author{
Arathy Puthillam ${ }^{1}$ and Hansika Kapoor ${ }^{1,2}$ \\ ${ }^{1}$ Department of Psychology, Monk Prayogshala \\ ${ }^{2}$ Neag School of Education, University of Connecticut, CT, USA
}

Author Note

Arathy Puthillam $^{1}$ (D) https://orcid.org/0000-0003-2426-8362

Hansika Kapoor (iD https://orcid.org/0000-0002-0805-7752

Note: This is a preprint, meaning that this manuscript has not undergone peer review.

The present study was not funded by any particular grant or organization.

Correspondence concerning this article should be addressed to Arathy Puthillam,

Department of Psychology, Monk Prayogshala (Sec 8), 4114, C Wing, Oberoi Garden

Estates, Powai, Mumbai 400072, Maharashtra, India.

E-mail: ar@monkprayogshala.in

${ }^{1}$ AR and HK conceptualized the study, AR and HK contributed to data preparation, collection, and analysis. AR and HK contributed to report writing and editing. 


\begin{abstract}
The relationship between ideology and partisanship is understudied in India. Using secondary data, we ask whether ideology predicts party preferences, and whether Indians can be clustered with respect to their ideological positions. To do so, we define ideology as differing along two dimensions: adherence to social norms and obedience to hierarchies. We find that a preference for hierarchies significantly determines which party is preferred compared to NOTA, whereas adherence to social norms significantly predicts voting for a number of left- and right-positioning parties. Second, a cluster analysis shows three clusters, which have been named "social reformists" for individuals who are left leaning on both dimensions, "disguised traditionalists" for those who are left leaning in terms of social norms, but right leaning in terms of adherence to hierarchies, and "traditionalists," for those who are right leaning in terms of both dimensions. Implications and future directions are discussed.
\end{abstract}

Keywords: ideology in India, political methodology, cluster analysis, voting behaviours, political psychology 


\section{I vote NOTA: Ideological Expanses of Partisanship in India}

Despite the fact that ideological issues are limited for political parties at a given point of time (Lowery et al., 2013; van de Wardt et al., 2021), India continues to have a multi-party system with hundreds of political parties. On the other hand, it has been argued that political parties in India (Suri et al., 2016), like in other newer democracies (Diamond \& Gunther, 2001; Mainwaring, 1999), are non-ideological. However, it is likely that ideology in India is likely to present differently as compared to traditional western politics. The present paper aims to understand whether ideology predicts party preferences in India and how Indians can be clustered based on their ideologies.

\section{Ideology in India}

Previous theoretical work has indicated that ideological conflicts in post-Independence India have revolved around issues of whether the state should accommodate marginalized groups (politics of recognition) and whether it should regulate norms (politics of statism; Chibber \& Verma, 2018).

The question of the role of the state in what is traditionally considered social issues in political science literature is likely to be the root of political ideology in India (Chhibber \& Verma, 2018). For instance, conservative thinking in India is that the state should not burden itself with transformation in social and economic domains, whereas liberals are likely to prefer state intervention in various issues.

Similarly, Jaffrelot (2017) has considered two criteria to define sociocultural ideologies in India: the persistence of non-individualistic values (e.g., the extended family) and attachment to religious values (e.g., traditionalism). 
It has been argued that economic ideology is not persistent in describing ideology in India (Chhibber \& Verma, 2021). Naseemullah (2017) traces the history of economic ideology in India, where historically, there were arguments for a moral economy based on social norms. Particularly, the free market, as advocated by the British, led to a drainage of wealth outwards (Chandra, 1966), which led to a distrust in the free market economy. Additionally, there was also a sentiment of not trusting the state, which was thought of as coercive, and thus, there was opposition to the Nehru-era planned economy. This has changed in recent years, as argued by Palshikar (2017); specifically, more recently, the interwoven elements of majoritarianism and development has inspired both corporate India and majoritarian elements to vote for the BJP (Bharatiya Janta Party), through collaborations between the state and capital, or what is popularly known as the 'Gujarat model' (see also Jaffrelot, 2015).

Individual differences in ideology have been formulated as falling along two dimensions: social norms and hierarchies (Puthillam et al., 2021), based on their issue positions. Social norms includes issues such as migration and LGBTQ+ rights, whereas hierarchies include issues such as nationalism and vigilance. The present study utilizes this approach to explore whether and how individual differences in political ideology predict party preferences and whether Indians can be clustered into groups based on their issue positions.

\section{Party Systems in India}

Though there are numerous parties in India, there is a significant variation in the effective number of parties across states and across time. The third party system, based on Yadav's (1999) rubrik, saw the growth of coalitional governments before 2014, following a realignment of party politics after 1989. Vaishnav and Hinston (2019) state that: “Although the Congress's grasp on national power had gradually weakened in the 1960s and 1970s, by the end of the following 
decade it had completely given way to a multipolar constellation of forces in which the Congress was no longer the single pole around which politics revolved." In other words, the number of parties competing for elections increased after 1989. Due to increasing electoral competition between parties leading to a division of vote share and smaller margins for victories, the effective number of parties is often low. This is especially the case as politicians switch parties to further their own careers (Chhibber et al., 2014).

Further, Vaishnav and Hilton (2019) also argue that since 2014 India has dawned on a fourth party system, characterised by a historic decline in vote share by Congress, and a single non-Congress party claiming a majority in the parliament. The 2019 elections saw a mandate for the BJP despite anti-incumbency, lapsed promises, and coordinated efforts of opposition parties. Further, the BJP saw support from eastern states of India, where cultural and linguistic identities are salient, unlike previous election cycles, as well as from all Hindu caste groups.

Such a shift in electoral politics also begs the question: what are the factors leading to party preferences in India? So far, Indian politics has been conceptualized as identity politics at its core, with caste and religious compositions playing an important role when determining which party may win in a particular electoral constituency. However, more recently, identitybased politics has not resulted in stable results, as seen in the 2019 elections. Though caste and religious identities continue to play an important role in Indian politics (Venkataramakrishnan, 2019), these are not the only things that matter.

\section{The Present Study}

In the present study, we assess whether ideological beliefs affect party preferences, and whether ideological preferences can be clustered together to understand party preferences. We utilize openly available secondary data from (Puthillam et al., 2021) to ask two questions: 
RQ1: Does ideology predict partisanship in the Indian context?

RQ2: What are the profiles of individuals with respect to their political ideology?

\section{Method}

The reader is directed to the original dataset from Puthillam et al (2021) to determine participant characteristics and data collection procedures.

\section{Materials}

Political Ideology Scale (Puthillam et al., 2021).

This scale consists of 31 items covering issues of ideological interest in India. Three subscales were identified: economic ideology $(M=18.07, S D=4.65)$, norms $(M=27.86, S D=$ 14.61), and hierarchies $(M=46.69, S D=13.69)$. The authors caution that economic ideology may not be relevant based on previous work and factor structures. Therefore, in this paper, economic ideology will be deemphasized.

\section{Self-Reported Awareness}

Awareness about political issues in India was measured through a single item using a 7point rating scale $(1=$ Not at all aware, $7=$ Extremely aware; $M=4.82, S D=1.44)$.

\section{Self-Reported Interest}

Interest about political issues in India was measured through a single item using a 7-point rating scale $(1=$ Not at all interested, $7=$ Extremely interested; $M=4.49, S D=1.81)$.

\section{Political Party Preference}

Participants indicated their political party preference by responding to the question: "If there were to be an election tomorrow, which of these political parties would you vote for?" They were provided with a list of the seven national parties in India, an option for the Aam 
Aadmi Party (AAP), and an option for NOTA. They were also provided with a textbox where they could write in their preference.

\section{RQ1: Does ideology predict partisanship in the Indian context?}

\section{Results}

To assess whether ideology predicts partisanship (RQ1), a multinomial logit regression of political ideology on partisanship was estimated and relative risk ratios were computed using $\mathrm{R}$, with NOTA as the reference category (Table 1a).

For norms, relative to voting NOTA, conservative beliefs about cultural norms positively predicted preference for the following parties: AITC, BJP, BSP, and INC, and NCP. For hierarchies, relative to voting NOTA, individuals with more conservative beliefs were less likely to vote for AAP, and more likely to vote for BJP. For economic ideology, relative to voting NOTA, conservative beliefs negatively predicted preferences for AAP and BSP.

The higher one's self-reported awareness about politics, the more likely they were to vote for CPI (Table 1b), compared to NOTA. The higher one's self-reported interest in politics, the more likely they were to vote AAP, CPI(M), and MNS.

Further, the more right one leaned in terms of self-reported political ideology, the more likely they were to vote for the BJP, and the less likely they were to vote for CPI, compared to NOTA. The more right leaning one is in terms of self-reported social issues, the more likely one is to vote for the BJP, and the less likely one is to vote for the BSP, compared to NOTA. For economic issues, the more they reported themselves to be right-leaning, the more they preferred CPI and NCP, compared to NOTA. 
Table 1a

Multinomial logit regression and risk ratios predicting partisanship based on ideological scale

\begin{tabular}{|c|c|c|c|c|c|c|c|c|c|c|c|}
\hline & AAP & AITC & BJP & BSP & CPI & CPIM & DND & INC & MNS & $\mathrm{NCP}$ & Other \\
\hline & 1 & 2 & 3 & 4 & 5 & 6 & 7 & 8 & 9 & 10 & 11 \\
\hline \multirow[t]{2}{*}{ Norms } & 1.01 & $1.145^{* * *}$ & 1.011 & $1.156^{* * *}$ & 1.052 & $1.062^{* * *}$ & 1.04 & $1.035^{* * *}$ & 1.037 & $1.061^{* * *}$ & 1 \\
\hline & -0.015 & -0.043 & -0.01 & -0.048 & -0.032 & -0.021 & -0.032 & -0.012 & -0.079 & -0.018 & -0.037 \\
\hline \multirow[t]{2}{*}{$\begin{array}{l}\text { Hierarch } \\
\text { ies }\end{array}$} & $0.957^{\text {*** }}$ & $0.908^{*}$ & $1.094^{* * *}$ & $0.902^{* *}$ & 0.986 & $0.926^{* * *}$ & 0.978 & $0.975^{*}$ & 0.995 & 1 & 1.005 \\
\hline & -0.014 & -0.056 & -0.013 & -0.053 & -0.043 & -0.028 & -0.039 & -0.014 & -0.085 & -0.028 & -0.035 \\
\hline \multirow{2}{*}{$\begin{array}{l}\text { Economi } \\
\text { c } \\
\text { Ideology }\end{array}$} & $0.924^{* *}$ & $0.769^{* *}$ & 1.035 & $0.611^{* * *}$ & 0.909 & 0.96 & 0.938 & 1.015 & 0.793 & 1.021 & 0.94 \\
\hline & -0.033 & -0.116 & -0.029 & -0.131 & -0.106 & -0.063 & -0.097 & -0.035 & -0.223 & -0.065 & -0.089 \\
\hline \multirow[t]{2}{*}{ Constant } & $7.651^{* * *}$ & 1.114 & $0.003^{* * *}$ & $23.570^{*}$ & 0.068 & 0.843 & 0.099 & 0.312 & 0.118 & $0.010^{* *}$ & 0.096 \\
\hline & -0.75 & -2.398 & -0.883 & -1.711 & -2.64 & -1.355 & -2.315 & -0.881 & -4.712 & -1.841 & -2.17 \\
\hline
\end{tabular}

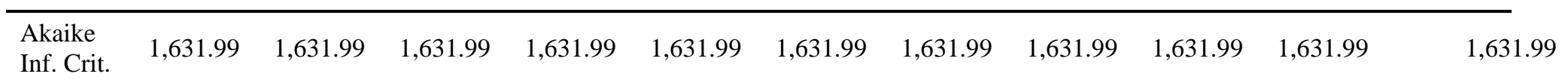

Note: $\quad{ }^{*} \mathrm{p}<0.1 ;{ }^{* *} \mathrm{p}<0.05 ;{ }^{* * *} \mathrm{p}<0.01$ 
Table 1b

Multinomial logit regression and risk ratios predicting partisanship based on self-reported ideology

\begin{tabular}{|c|c|c|c|c|c|c|c|c|c|c|c|}
\hline & AAP & AITC & BJP & BSP & CPI & CPIM & DND & INC & MNS & $\mathrm{NCP}$ & Other \\
\hline & -1 & -2 & -3 & -4 & -5 & -6 & -7 & -8 & -9 & -10 & -11 \\
\hline \multirow[t]{2}{*}{$\begin{array}{l}\text { Awarene } \\
\text { ss }\end{array}$} & 1.049 & 1.276 & $1.232^{*}$ & 1.062 & $3.599^{* *}$ & 0.689 & 0.62 & 1.229 & 0.81 & $0.682^{*}$ & 0.805 \\
\hline & -0.144 & -0.474 & -0.106 & -0.464 & -0.554 & -0.271 & -0.381 & -0.129 & -1.046 & -0.231 & -0.34 \\
\hline \multirow[t]{2}{*}{ Interest } & $1.462^{* * *}$ & 1.019 & 1.09 & 1.437 & 0.804 & $1.974^{* * *}$ & 1.567 & 0.936 & $\begin{array}{c}664,355 \\
300^{* * *}\end{array}$ & 1.23 & 1.543 \\
\hline & -0.119 & -0.355 & -0.083 & -0.382 & -0.257 & -0.25 & -0.335 & -0.1 & -0.942 & -0.206 & -0.312 \\
\hline \multirow{2}{*}{$\begin{array}{l}\text { Self- } \\
\text { reported } \\
\text { political } \\
\text { ideology }\end{array}$} & 0.816 & 0.86 & $1.309^{* *}$ & 0.685 & $0.333^{* *}$ & 0.906 & 0.896 & 1.019 & 1.016 & 0.881 & 1.843 \\
\hline & -0.152 & -0.444 & -0.119 & -0.354 & -0.442 & -0.306 & -0.415 & -0.149 & -0.759 & -0.224 & -0.404 \\
\hline \multirow{2}{*}{$\begin{array}{l}\text { Self- } \\
\text { reported } \\
\text { social } \\
\text { ideology }\end{array}$} & 0.873 & 1.245 & $1.273^{* * *}$ & $1.671^{*}$ & 0.963 & 0.813 & 1.163 & 1.125 & 1.603 & 1.159 & 0.71 \\
\hline & -0.115 & -0.336 & -0.086 & -0.264 & -0.319 & -0.235 & -0.279 & -0.107 & -0.684 & -0.173 & -0.302 \\
\hline $\begin{array}{l}\text { Self- } \\
\text { reported } \\
\text { economi } \\
\text { c } \\
\text { ideology }\end{array}$ & 1.065 & 1.293 & 1.056 & 1.051 & $2.183^{* *}$ & 0.827 & 0.725 & 0.862 & 0.959 & $1.633^{* *}$ & 0.7 \\
\hline
\end{tabular}




\begin{tabular}{|c|c|c|c|c|c|c|c|c|c|c|c|}
\hline & AAP & AITC & BJP & BSP & $\mathrm{CPI}$ & CPIM & DND & INC & MNS & $\mathrm{NCP}$ & Other \\
\hline & -1 & -2 & -3 & -4 & -5 & -6 & -7 & -8 & -9 & -10 & -11 \\
\hline \multirow{3}{*}{ Constant } & -0.134 & -0.447 & -0.112 & $\begin{array}{l}-0.369 \\
\end{array}$ & -0.319 & -0.269 & $\begin{array}{l}-0.396 \\
\end{array}$ & -0.141 & $\begin{array}{l}-0.642 \\
\end{array}$ & -0.226 & -0.365 \\
\hline & $0.113^{* * *}$ & $0.002^{* *}$ & $0.029^{* * *}$ & $0.002^{* * *}$ & $\underset{*}{0.0001^{* *}}$ & $0.077^{* *}$ & 0.098 & $0.194^{* * *}$ & $0.000^{* * *}$ & $0.027^{* * *}$ & $0.016^{* *}$ \\
\hline & -0.67 & -2.439 & -0.567 & -2.373 & -3.36 & -1.216 & -1.583 & -0.631 & -0.135 & -1.157 & -1.694 \\
\hline AIC & $1,728.90$ & $1,728.90$ & $1,728.90$ & $1,728.90$ & $1,728.90$ & $1,728.90$ & $1,728.90$ & $1,728.90$ & $1,728.90$ & $1,728.90$ & $1,728.90$ \\
\hline
\end{tabular}




\section{Discussion}

We find that ideological preferences for hierarchies and deference towards authorities significantly determine which party is preferred. However, this is true only in terms of AAP (left-presenting), BJP (right-presenting), and NOTA. On the other hand, with respect to cultural norms, the AITC, INC, NCP, as well as BSP and BJP all are different from NOTA in the same direction. This implies that those who prefer these parties all lean towards the right in terms of endorsement of cultural norms.

Awareness and interest did affect one's party preferences, but only as it related to the leftpresenting parties. On the other hand, self-positioning scores affected preference for only a few parties.

\section{RQ2: What are the profiles of individuals with respect to their political ideology?}

\section{Analysis Steps}

The political ideology scales were standardized using the "scale" function in base R. This is a recommended step to make the variables comparable.

The "cluster" (Maechler et al., 2021) and "factoextra" (Alboukadel \& Mundt, 2020) packages from $\mathrm{R}$ were used to perform and visualize the cluster analyses. Then, ANOVAs and $\mathrm{t}-$ tests were used to compare the clusters with respect to the factor scores (i.e., norms, hierarchies, and economic ideology) and the item scores. Next, the percentage of vote share for each cluster was calculated. Finally, cluster validation was performed using the "fpc" package (Hennig, 2020). Specifically, the dunn index, a metric for assessing whether the clusters have a small variance between members, and a large variance or distance between clusters, was computed. The distance within the clusters should be small, and that between clusters should be large. Thus, the index should have a large value (range: 0 to infinity) for the clustering to be considered valid. 
The Rand index was also computed. The Rand index is an external validation tool, implying that the clusters are compared to an existing dataset. Here, the external data were the subfactor scores. The Rand index assessed similarity between the two clusters, and the range of the index is -1 (no agreement) to 1 (perfect agreement).

Though K-Means is probably the more popular method for clustering, it is sensitive to outliers. Our data presented outliers (see Figure 1). The partitioning around medoids (PAM; Kaufman \& Rousseeuw, 1990) method is a robust alternative, as it is less sensitive to outliers. Thus, PAM was used. Here, each cluster is represented by a particular individual, who is considered representative of the cluster. The "pam" method in the "factoextra" package was used to estimate the optimal number of clusters.

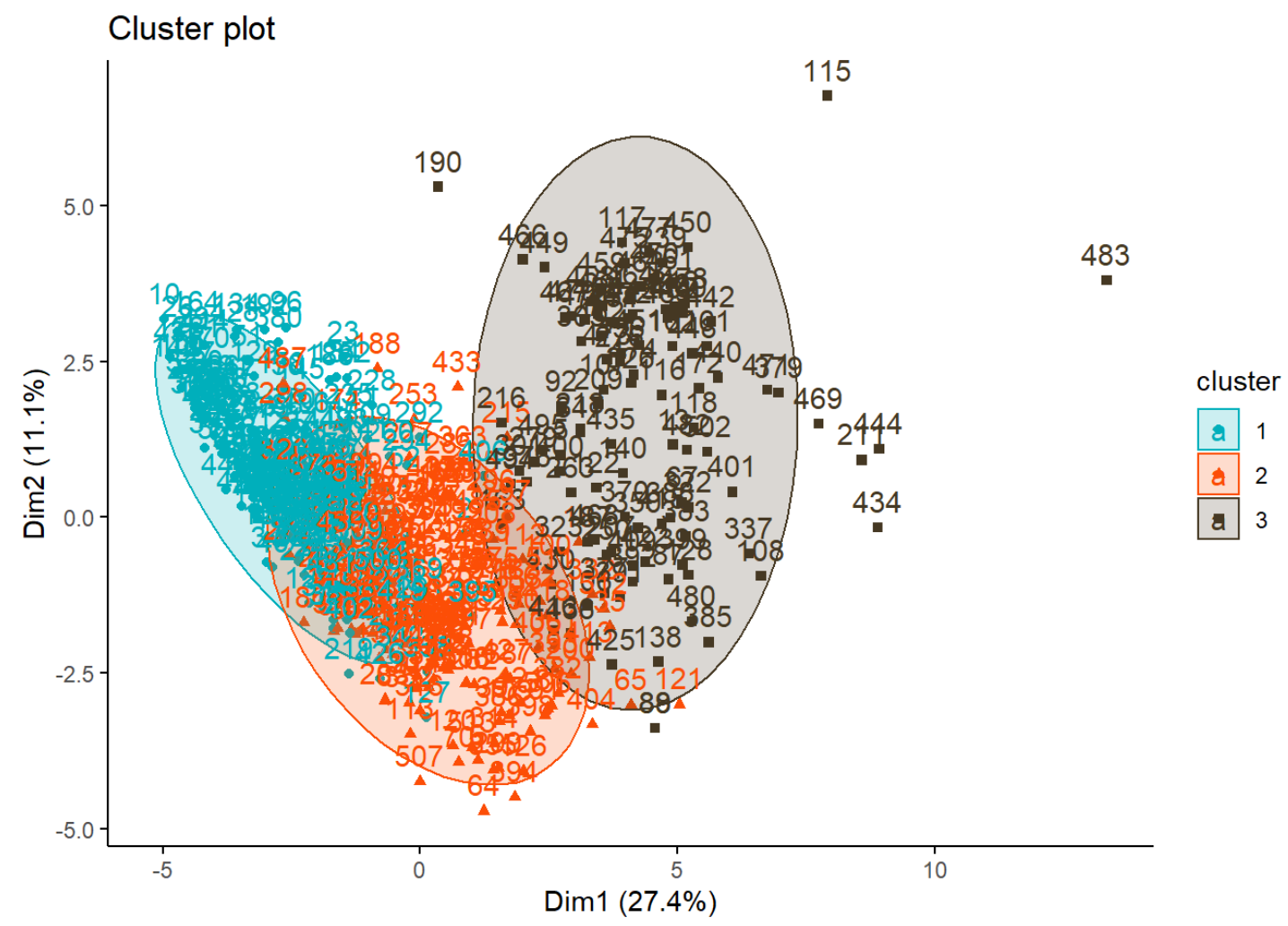

Figure 1. Cluster Analysis 


\section{Results}

The appendix presents a summary of the 2-4 clusters attempted through K-Means as well as PAM. A 3-cluster solution using PAM seems the most appropriate. This decision was made based on both internal and external validation (the dunn and Rand index) as well as based on the overlap between clusters. Specifically, the 2 cluster solution had a lower Rand index, and individuals with preferences for left- and right-leaning parties were clustered together and the four cluster solution had a significant overlap.

In the three-cluster solution, all items were significantly different across clusters, except "reduce wealth differences." Scores on all factors were significantly different [norms: F(184, 2) $=143.905, \mathrm{p}<.001$; hierarchies: $\mathrm{F}(203,2)=297.441, \mathrm{p}<.001$; economic ideology: $\mathrm{F}(192,2)=8.48$, $\mathrm{p}<.001]$. The clusters differ on self-reported political $[\mathrm{F}(173,2)=22.77, \mathrm{p}<.001]$, social $[\mathrm{F}(181$, $2)=29.97, p<.001]$, and economic ideology $[F(182,2)=10.36, p<.001]$. Each cluster was significantly different from each other for both norms and hierarchies. For economic ideology, clusters 1 and 2 were not significantly different ( $\mathrm{p}=.995)$. Clusters 2 and 3 were not significantly different with respect to self-reported political ideology $(p=.818)$, social issues $(p=1.00)$, and economic issues $(\mathrm{p}=.742)$.

See Table $2 \mathrm{a}$ for party preferences in each cluster and $2 \mathrm{~b}$ for party preferences across the identified clusters. 
Table 2a.

Participants' party preferences per cluster.

\begin{tabular}{lrrrrrr}
\hline Political & \multicolumn{1}{c}{$\boldsymbol{1}$} & \multicolumn{2}{c}{$\mathbf{2}$} & $\mathbf{3}$ \\
\cline { 2 - 7 } Parties & $\boldsymbol{N}$ & $\boldsymbol{\%}$ & $\boldsymbol{N}$ & $\boldsymbol{\%}$ & $\boldsymbol{N}$ & $\mathbf{\%}$ \\
\hline AAP & 54 & 20.77 & 11 & 5.91 & 5 & 7.35 \\
AITC & 4 & 1.54 & 0 & 0 & 0 & 0 \\
BJP & 34 & 13.08 & 82 & 44.09 & 33 & 48.53 \\
BSP & 4 & 1.54 & 0 & 0 & 1 & 1.47 \\
CPI & 2 & 0.77 & 1 & 0.54 & 2 & 2.94 \\
CPIM & 12 & 4.62 & 1 & 0.54 & 2 & 2.94 \\
DND & 3 & 1.15 & 2 & 1.08 & 1 & 1.47 \\
INC & 44 & 16.92 & 13 & 6.99 & 5 & 7.35 \\
MNS & 0 & 0 & 1 & 0.54 & 0 & 0 \\
NCP & 8 & 3.08 & 5 & 2.69 & 2 & 2.94 \\
NOTA & 92 & 35.38 & 68 & 36.56 & 15 & 22.06 \\
Other & 3 & 1.15 & 2 & 1.08 & 2 & 2.94 \\
\hline Total & 260 & 100 & 186 & 100 & 68 & 100 \\
\hline
\end{tabular}

Table 2b.

Participants' party preferences across the identified clusters

\begin{tabular}{lrrr}
\hline $\begin{array}{l}\text { Political } \\
\text { Parties }\end{array}$ & Cluster & Cluster & Cluster \\
\hline AAP & 10.51 & 2.14 & 0.97 \\
AITC & 0.78 & 0 & 0 \\
BJP & 6.61 & 15.95 & 6.42 \\
BSP & 0.78 & 0 & 0.19 \\
CPI & 0.39 & 0.19 & 0.39 \\
CPIM & 2.33 & 0.19 & 0.39 \\
DND & 0.58 & 0.39 & 0.19 \\
INC & 8.56 & 2.53 & 0.97 \\
MNS & 0 & 0.19 & 0 \\
NCP & 1.56 & 0.97 & 0.39 \\
NOTA & 17.9 & 13.23 & 2.92 \\
Other & 0.58 & 0.39 & 0.39 \\
\hline Total & 50.58 & 36.19 & 13.23 \\
\hline
\end{tabular}


The dunn index for this solution was .14, the Rand index for norms was .048, hierarchies was .023, and economic ideology was 0.003 .

In the three-cluster solution, however, it is evident that the second cluster overlaps with the otherwise independent first and third clusters, graphically as well as statistically (average silhouette width $=.04)$. It may be interpreted that the second cluster consists of individuals who have both left- and right-leaning tendencies.

\section{Discussion}

Using K-Means and PAM, we identified three clusters within which an individual falls with respect to political ideology in India.

\section{Cluster Labels}

The first cluster primarily voted for left-positioned parties such as the CPI(M) and AAP. They also had lower scores on norms and hierarchies, implying a tendency to lean left on what may be considered social issues. They also self-positioned themselves as leaning left on political, economic, and social issues. Thus, the first cluster may be considered as a left-leaning individual, and hence may be labelled as "social reformists." However, it is particularly noteworthy that a large proportion within this cluster also preferred voting for the BJP. This might imply that ideology may not necessarily be the only factor for partisanship in India, and the two cannot be used exchangeably. However, this also shows that ideology is not completely distinct from partisanship.

The second cluster voted primarily NOTA or for the BJP. Compared to the first cluster, they lean left with respect to endorsement of cultural norms. However, they lean right with respect to adherence of obedience. On the other hand, they lean left with respect to both norms and hierarchies compared to cluster 3 . When self-reporting their ideology, however, they rate 
themselves as significantly different only compared to cluster 1 , and not cluster 3 . Thus, individuals within this group may be considered having higher degrees of authoritarian submission (Funke, 2005), but lower levels of conventionalism (Altemeyer, 1996). This group may be labelled "disguised traditionalists."

The third cluster primarily voted for the BJP and NOTA. Compared to the first and the second cluster, they reported themselves to be significantly right-leaning in terms of norms, hierarchies. Compared to the first cluster, they were more right leaning in terms of self-reported political ideology and social issues, but not economic issues. Thus, the individuals within this group may be considered right-leaning, and may be labelled traditionalists.

\section{General Discussion}

Conservatism is often associated with middle-class resistance to lower-class demands, where the "haves" would prefer to keep what they have (Erdman, 1967). However, considering that divergent traditions exist in India, and because defenders of tradition may not defend the same kinds of traditions, more research is required when trying to define conservatism in India. The present study aimed to understand the relationships between political ideology, especially as it may concern issue positions, and partisanship in India, through two research questions.

The first question aimed to assess whether there was a difference between those who voted NOTA and those who preferred the other parties in terms of adherence to norms and obedience to hierarchies. We found that individuals who vote for the AITC, BJP, BSP, INC, and NCP significantly differ from those who prefer NOTA in terms of adherence to cultural norms. Further, those who vote for the BJP and AAP significantly differ from those who vote NOTA in terms of their obedience to hierarchical authority. 
The second question aimed to profile Indians in terms of their ideology and party preferences. We found that Indians fall along three clusters. The first and the third clusters seem distinct in terms of their issue positions and party preferences: the first clustered, labelled social reformists leaned left in terms of both issues and parties, whereas the third, labelled traditionalists leaned right. The second cluster of individuals lean left on some normative issues, but right in terms of both party preference as well as on issues about authorities and hierarchies. They were labelled as disguised traditionalists, following Erdman's () view that a certain segment of the Indian conservative (who he calls disguised conservatives), though professing a need for change with respect to some parts of the Indian life, in effect is supportive of other hierarchical systems, such as the caste system. In other words, though they may profess change in normative aspects of politics, they are supportive of the status quo.

In a dynamic time in ideological and party politics in India, these findings have specific importance. Though it is unclear what leads to vote choice within the Indian context, the present study highlights how ideology and party preferences are not completely divorced, as has been previously speculated and popularly argued. Future work should attempt to assess demographic characteristics as well as attempt different methodologies in understanding the relationship between ideology and partisanship in India. For instance, future research could attempt to use ranked-choice methods to understand party preferences. Future work could also attempt to explore voter-party linkages by using parallel surveys of party elites and citizens (e.g., Stoetzer \& Zittlau, 2020). Further, these findings have applicability in better understanding political communication and political psychology. For instance, do the three clusters respond to political campaigns and political communication differently? 
The present study was not without its limitations. First, demographic characteristics of age and gender were assessed, however, other important caveats such as caste and religion were not included in this dataset. Future research should assess such vital information. Second, the issue space in India is dynamic, and the present dataset does not assess information about religious polarization as has been increasingly important in public imagination more recently. Third, a majority of the participants responded "NOTA" when asked about party preferences. This may be an issue with sampling; however, it also more likely to be the case that those who do not prefer any of the parties may not vote at all. Future research should attempt to better understand the NOTA vote. The parties presented in the present study were largely national-level parties. Similarly, the present study was conducted in English; future research may translate the scale into various regional languages, which might also help in understanding regional-level differences and regional-level parties.

In sum, the present study attempted to understand the relationships between partisanship and ideology in India. We found that there were significant differences in partisanship when considering adherence towards social norms and hierarchical authorities. In other words, we found evidence for partisanship among individuals who differ in social or cultural dimensions of ideology. Second, we found that individuals in India can be clustered into three categories depending on their issue positions: social reformists, disguised traditionalists, and traditionalists. In doing so, we found further evidence for ideological differences in party preferences in India. 


\section{References}

Alboukadel, K., \& Mundt, F. (2020). factoextra: Extract and Visualize the Results of Multivariate Data Analyses (1.0.7) [Computer software]. ttps://CRAN.Rproject.org/package $=$ factoextra

Altemeyer, B. (1996). The authoritarian specter. Harvard Univ. Press.

Chandra, B. (1966). The Rise and Growth of Economic Nationalism in India: Economic Policies of Indian National Leadership, 1880-1905. People's Publishing House. https://scholar.google.com/scholar_lookup?hl=en\&publication_year=1966\&author=Bipa $\mathrm{n}+$ Chandra\&title $=$ The + rise + and + growth + of + economic + nationalism + in + India

Chhibber, P. K., \& Verma, R. (2018). Intellectual Lineages of the Politics of Statism and Recognition (Vol. 1). Oxford University Press. https://doi.org/10.1093/oso/9780190623876.003.0004

Chhibber, P. K., \& Verma, R. (2021). Economic Ideology and Indian Politics: Absence of class divide and Emerging Contestation over the role of State. In Electoral Trends and Voting Behaviour in India: 1996-2019.

Diamond, L., \& Gunther, R. (2001). Political parties and democracy. JHU Press.

Erdman, H. (1967). Swatantra Party and Indian conservatism. Cambridge University Press. ark:/13960/t5s 770532

Funke, F. (2005). The Dimensionality of Right-Wing Authoritarianism: Lessons from the Dilemma between Theory and Measurement. Political Psychology, 26(2), 195-218. https://doi.org/10.1111/j.1467-9221.2005.00415.x

Hennig, C. (2020).fpc: Flexible Procedures for Clustering (2.2-9) [Computer software]. https://CRAN.R-project.org/package $=\mathrm{fpc}$ 
Jaffrelot, C. (2015). What 'Gujarat Model'?_-Growth without Development—And with SocioPolitical Polarisation: South Asia. South Asia: Journal of South Asian Studies, 38(4), 820-838. https://doi.org/10.1080/00856401.2015.1087456

Jaffrelot, C. (2017). The Roots and Varieties of Political Conservatism in India. Studies in Indian Politics, 5(2), 205-217. https://doi.org/10.1177/2321023017727968

Kaufman, L., \& Rousseeuw, P., J. (1990). Finding Groups in Data. John Wiley \& Sons, 2009. https://onlinelibrary.wiley.com/doi/book/10.1002/9780470316801

Lowery, D., van Witteloostuijn, A., Péli, G., Brasher, H., Otjes, S., \& Gherghina, S. (2013). Policy agendas and births and deaths of political parties. Party Politics, 19(3), 381-407. https://doi.org/10.1177/1354068811407576

Maechler, M., Rousseeuw, P., Struyf, A., Hubert, M., \& Hornik, K. (2021). Cluster: Cluster Analysis Basics and Extensions. $R$ package version 2.1.2 (2.1.2) [Computer software]. https://CRAN.R-project.org/package $=$ cluster

Mainwaring, S. (1999). Rethinking party systems in the third wave of democratization: The case of Brazil. Stanford University Press.

Naseemullah, A. (2017). The Political Economy of Economic Conservatism in India: From Moral Economy to Pro-business Nationalism. Studies in Indian Politics, 5(2), 233-247.

Palshikar, S. (2017). India's Second Dominant Party System. Economic and Political Weekly, 52(11). https://www.epw.in/journal/2017/11/web-exclusives/indias-second-dominantparty-system.html

Puthillam, A., Kapoor, H., \& Karandikar, S. (2021). Beyond left and right: A scale to measure political ideology in India [Preprint]. https://psyarxiv.com/fg387/ 
Stoetzer, L. F., \& Zittlau, S. (2020). Vote Choice and the Nonseparability of Economic and Social Issues. Public Opinion Quarterly, 84(1), 158-170. https://doi.org/10.1093/poq/nfaa005

Suri, K. C., Elliott, C., \& Hundt, D. (2016). Democracy, governance and political parties in India: An introduction. Studies in Indian Politics, 4(1), 1-7.

Vaishnav, M., \& Hintson, J. (2019). The Dawn of India's Fourth Party System. Carnegie Endowment for International Peace. https://carnegieendowment.org/2019/09/05/dawnof-india-s-fourth-party-system-pub-79759

van de Wardt, M., Berkhout, J., \& Vermeulen, F. (2021). Survival of the fittest. Comparing entry and exit among niche and mainstream parties in advanced democracies, 1945-2011. Electoral Studies, 69, 102261.

Venkataramakrishnan, R. (2019, June 5). Out-of-touch elitists? Actually BJP drew the most support from upper castes and the rich. Scroll.In. https://scroll.in/article/925925/areindias-elite-anti-bjp-actually-saffron-party-got-greatest-support-from-upper-castes-rich

Yadav, Y. (1999). Electoral politics in the time of change: India's third electoral system, 1989-99. Economic and Political Weekly, 2393-2399. 